\title{
Influence of Race, Income, Insurance, and Education on the Rate of Breast Reconstruction
}

\author{
DAVID J. RESTREPO ${ }^{1}$, DANIEL BOCZAR ${ }^{1}$, MARIA T. HUAYLLANI ${ }^{1}$, ANDREA SISTI ${ }^{1}$, \\ EMMANUEL GABRIEL ${ }^{2}$, SARAH A. MCLAUGHLIN ${ }^{2}$, SANJAY BAGARIA ${ }^{2}$, \\ AARON C. SPAULDING ${ }^{3}$, BRIAN D. RINKER ${ }^{1}$ and ANTONIO J. FORTE ${ }^{1}$ \\ ${ }^{I}$ Division of Plastic Surgery and Robert D. and Patricia E. Kern Center \\ for the Science of Health Care Delivery, Mayo Clinic, Jacksonville, FL, U.S.A.; \\ ${ }^{2}$ Department of Surgery, Mayo Clinic, Jacksonville, FL, U.S.A.; \\ ${ }^{3}$ Department of Health Science Research, Mayo Clinic, Jacksonville, FL, U.S.A.
}

\begin{abstract}
Background/Aim: The aim of this study was to analyze how race, income, insurance, and education, affect breast reconstruction rates. Materials and Methods: We reviewed the National Cancer Database. $\chi^{2}$ test and binary logistic regression were used to analyze the association between demographic characteristics and reconstruction rate. Results: White race and private insurance were associated with a higher risk of getting reconstruction when compared to black race (odd ratio $[O R]=0.939 ; 95 \% C I=0.909-0.970$ ) and government insurance $(O R=0.459 ; 95 \% C I=0.447$ 0.471). Patients with an estimated income $>\$ 63,000$ were found to have higher odds of receiving breast reconstruction than patients with income less than $\$ 38,000$ (OR=1.868; 95\%CI=1.792-1.948). Patients who live in a zip code area with a higher education average have higher odds of receiving postmastectomy breast reconstruction than patients living in a zip code with a lower education average $(O R=1.152,95 \% C I=1.104-1.203)$. Conclusion: Differences in reconstruction rates exist based on race, income, insurance, and education level.
\end{abstract}

The United States has 3.5 million breast cancer survivors, and with the improvement of breast cancer treatment, this number is expected to increase (1). Survival is not the only challenge with breast cancer; women undergo surgeries that affect the appearance of their breast and their body image.

Correspondence to: Antonio Jorge Forte, MD, Ph.D., Mayo Clinic, 4500 San Pablo Road, Jacksonville, FL 32224, U.S.A. Tel: +1 9049532073,e-mail: ajvforte@yahoo.com.br

Key Words: Breast neoplasms/surgery, female, healthcare disparities/statistics \& numerical data, mastectomy, middle aged, retrospective studies.
Many female survivors who undergo breast reconstruction report improvements in quality of life, satisfaction with appearance, and overall sexuality (2, 3). The Women's Health and Care Rights Act was passed in 1998, mandating that health insurance companies cover postmastectomy breast reconstruction (4). In 2010, the Patient Protection and Affordable Care Act was approved, requiring physicians to discuss the option of breast reconstruction and coverage by insurance with patients who will undergo a mastectomy. If the patient is not covered in that institution, the physician must remit them to an institution at which they are covered (5). These laws were passed with the intention of improving access to breast reconstruction, thus reducing disparities among patients undergoing reconstruction (5). Although some studies using national databases have shown a downtrend in disparities in recent years, they are still present (6-13). Socioeconomic disparities, such as race, income, insurance, and education, have been proven to affect breast reconstruction rates $(7,14-18)$.

We hypothesize that, despite the laws, increased awareness, and a higher rate of reconstruction, there are still disparities in favor of white race, higher income, private insurance, and higher education level.

\section{Materials and Methods}

Data source. The NCDB is a program of the Commission on Cancer of the American College of Surgeons and the American Cancer Society that collects information for approximately $70 \%$ of the newly diagnosed cancer patients in USA $(19,20)$. The data are submitted by Certified Tumor Registrars who are trained to enter patient information into the NCDB. The data are revised and, if found incomplete or inaccurate, sent back to the submitting institution for correction (20). The information included in this database allowed us to perform a retrospective cohort study in which the NCDB was queried for patients with breast cancer diagnosed between January 1st, 2004 and December 31st, 2015. Our 
study was exempt from institutional review board evaluation due to its population-based nature with no identifiers.

Study sample. We included patients diagnosed with breast cancer (disease stages I, II, and III), 18 years of age and older, who had a reported mastectomy in the variable "Surgical Procedure of the Primary Site". Patients who had a reported reconstruction were also included in the mastectomized group because, to get a reconstruction, the patient must have had a mastectomy. We excluded patients who were male or had stage IV disease. Male patients were excluded because they do not undergo reconstruction, and those with stage IV disease were excluded due to a known low rate of reconstruction in this population (18). Figure 1 outlines our inclusion and exclusion criteria.

Dependent variables. The NCDB variable "Surgical Procedure of the Primary Site" was assessed to determine if patients who received mastectomy had also received immediate or early delayed reconstruction. A filter was applied to the database and the analyzed variable was recoded to separate patients based on reconstruction status (reconstruction versus no reconstruction). It is important to clarify that the NCDB collects information of patients with cancer during their primary treatment only. This means that only patients who received immediate or early delayed breast reconstruction (part of their primary treatment) will have a reported breast reconstruction. However, patients who received reconstruction after their primary treatment will not have a reported reconstruction procedure and will appear on the database with a mastectomy procedure only (18).

Explanatory variables. The following variables were used for the study: facility type, age, race, Hispanic origin, insurance status, income (zip code's population average), education (percentage of people without high school diploma within the zip code of residence), and presence of comorbidities using the Charlson-Deyo Score (21). These covariates were selected because they could influence the rate of reconstruction in patients.

Statistical analysis. We examined the association between immediate or early delayed postmastectomy breast reconstruction versus no reconstruction. We compared the explanatory variables and rate of reconstruction using the $\chi^{2}$ test. We then ran a multivariate regression model to examine how patient-specific demographic characteristics influenced the probability of getting an immediate or early delayed breast reconstruction. Patients who had missing data were excluded from regression models. Significance was set at a $p<0.05$. Statistical analysis was performed using SPSS 25.0 statistical software (SPSS Inc., Chicago, IL, USA).

\section{Results}

The NCDB contains data for a total of 2,445,870 patients diagnosed with breast cancer during our study period. After applying inclusion and exclusion criteria, our cohort included a total of 876,472 patients (Figure 1).

The mean (SD) age of the included population was 58.79 (13.76) years. There were $730,004(83.3 \%)$ white patients, 97,125 (11.1\%) black patients, 32,064 (3.7\%) Asian patients, 2,482 (0.3\%) Native American patients, and 14,797 (1.7\%) patients without race information. The majority of the study
Table I. $\chi^{2}$ test of both groups.

\begin{tabular}{|c|c|c|c|c|c|}
\hline \multirow[b]{2}{*}{ Characteristics } & \multicolumn{2}{|c|}{$\begin{array}{l}\text { Postmastectomy } \\
\text { reconstruction }\end{array}$} & \multicolumn{2}{|c|}{$\begin{array}{l}\text { No postmastectomy } \\
\text { reconstruction }\end{array}$} & \multirow[b]{2}{*}{$p$-Value } \\
\hline & $\mathrm{N}$ & $\%$ & $\mathrm{~N}$ & $\%$ & \\
\hline Race & & & & & $<0.001$ \\
\hline White & 53388 & $85.80 \%$ & 469275 & $83.50 \%$ & \\
\hline Black & 6922 & $11.10 \%$ & 68343 & $12.20 \%$ & \\
\hline Asian & 1822 & $2.90 \%$ & 22391 & $4.00 \%$ & \\
\hline Native American & 122 & $0.20 \%$ & 1820 & $0.30 \%$ & \\
\hline Total & 62254 & $100.00 \%$ & 561829 & $100.00 \%$ & \\
\hline Insurance & & & & $<0.001$ & \\
\hline Private & 49827 & $79.20 \%$ & 253973 & $45.60 \%$ & \\
\hline Government & 12209 & $19.40 \%$ & 288913 & $51.80 \%$ & \\
\hline Not insured & 897 & $1.40 \%$ & 14486 & $2.60 \%$ & \\
\hline Total & 62933 & $100.00 \%$ & 557372 & $100.00 \%$ & \\
\hline Income & & & & & $<0.001$ \\
\hline$<\$ 38,000$ & 6966 & $11.10 \%$ & 102183 & $18.00 \%$ & \\
\hline$\$ 38,000-\$ 47,999$ & 28530 & $45.30 \%$ & 177216 & $31.30 \%$ & \\
\hline$\$ 48,000-\$ 62,999$ & 16412 & $26.00 \%$ & 152894 & $27.00 \%$ & \\
\hline$\$ 63,000+$ & 11095 & $17.60 \%$ & 133975 & $23.70 \%$ & \\
\hline Total & 63003 & $100.00 \%$ & 566268 & $100.00 \%$ & \\
\hline Education* & & & & $<0.001$ & \\
\hline $21 \%$ or more & 7438 & $11.80 \%$ & 98719 & $17.40 \%$ & \\
\hline $13 \%-20.9 \%$ & 21244 & $33.70 \%$ & 138667 & $24.50 \%$ & \\
\hline $7 \%-12.9 \%$ & 20674 & $32.80 \%$ & 182901 & $32.30 \%$ & \\
\hline Less than $7 \%$ & 13659 & $21.70 \%$ & 146259 & $25.80 \%$ & \\
\hline Total & 63015 & $100.00 \%$ & 566546 & $100.00 \%$ & \\
\hline
\end{tabular}

* Percentage of people without a high school diploma within the patient's zip code.

population was insured at the time of diagnosis: 488,798 (55.8\%) had private insurance, 352,348 (40.2\%) had government insurance, 18,617 (2.1\%) had no insurance and 16,709 (1.9\%) had an unknown insurance status. Table I outlines the demographic characteristics of the cohort and their percentage of reconstruction.

On multivariate analysis, (Table II) demographic characteristics had an effect on the rate of breast reconstruction after adjusting for confounders. Patients of black $(\mathrm{OR}=0.939 ; 95 \% \mathrm{CI}=0.909-0.97 ; p<0.001)$, Asian $(\mathrm{OR}=0.486 ; 95 \% \mathrm{CI}=0.459-0.515 ; p<0.001)$ and Native American $(\mathrm{OR}=0.615 ; 95 \% \mathrm{CI}=0.493-0.766 ; p<0.001)$ decent were found to have lower odds of receiving immediate or early delayed postmastectomy breast reconstruction when compared to white patients. Patients with government $(\mathrm{OR}=0.459 ; 95 \% \mathrm{CI}=0.447-0.471 ; p<0.001)$ or no insurance $(\mathrm{OR}=0.310 ; 95 \% \mathrm{CI}=0.286-0.336 ; p<0.001)$ had lower odds of receiving immediate or early delayed postmastectomy breast reconstruction when compared to patients who had private insurance. Furthermore, patients with an estimated income more than $\$ 63,000$ were found to have higher odds of receiving breast reconstruction than patients with an 
Table II. Multivariate analysis of the characteristics that affect the rate of postmastectomy breast reconstruction.

\begin{tabular}{|c|c|c|c|c|}
\hline \multirow[b]{2}{*}{ Characteristics } & \multicolumn{3}{|c|}{$\begin{array}{c}\text { Multivariate analysis } \\
95 \% \mathrm{CI}\end{array}$} & \multirow[b]{2}{*}{$p$-Value } \\
\hline & $\mathrm{aOR}$ & Lower & Upper & \\
\hline \multicolumn{5}{|l|}{ Race } \\
\hline White & 1 & & & \\
\hline Black & 0.939 & 0.909 & 0.97 & $<0.001$ \\
\hline Asian & 0.486 & 0.459 & 0.515 & $<0.001$ \\
\hline Native American & 0.615 & 0.493 & 0.766 & $<0.001$ \\
\hline \multicolumn{5}{|l|}{ Insurance } \\
\hline Private & 1 & & & \\
\hline Government & 0.459 & 0.447 & 0.471 & $<0.001$ \\
\hline Not insured & 0.310 & 0.286 & 0.336 & $<0.001$ \\
\hline \multicolumn{5}{|l|}{ Income* } \\
\hline$<\$ 38,000$ & 1 & & & \\
\hline$\$ 38,000-\$ 47,999$ & 1.15 & 1.107 & 1.195 & $<0.001$ \\
\hline$\$ 48,000-\$ 62,999$ & 1.386 & 1.333 & 1.441 & $<0.001$ \\
\hline$\$ 63,000+$ & 1.868 & 1.792 & 1.948 & $<0.001$ \\
\hline \multicolumn{5}{|l|}{ Education** } \\
\hline $21 \%$ or more & 1 & & & \\
\hline $13 \%-20.9 \%$ & 1.095 & 1.055 & 1.135 & $<0.001$ \\
\hline $7 \%-12.9 \%$ & 1.056 & 1.016 & 1.097 & 0.006 \\
\hline Less than $7 \%$ & 1.152 & 1.104 & 1.203 & $<0.001$ \\
\hline
\end{tabular}

*Average income in zip code of residence. **Percentage of people without a high school diploma within the patient's zip code. Adjusted for Hispanic Origin, age, facility type, Charlson Deyo Score.

income less than $\$ 38,000(\mathrm{OR}=1.868 ; 95 \% \mathrm{CI}=1.792-1.948$; $p<0.001)$. We also found that patients living in a zip code area where less than $7 \%$ of the population did not finish high school have higher odds of receiving postmastectomy breast reconstruction than patients living in a zip code area where more than $21 \%$ of the population did not graduate high school (OR=1.152; 95\% CI=1.104-1.203; $p<0.001)$.

\section{Discussion}

Breast reconstruction is a procedure that has a positive impact on quality of life, satisfaction with appearance, and overall sexuality on women undergoing mastectomy $(2,3)$. Hence, it should be equally available to every woman wishing to have a reconstruction, independent of demographic characteristic. Our analysis demonstrated the influence that race, income, insurance, and education have on whether patients get immediate or early delayed postmastectomy breast reconstruction.

In 2012, a study comparing rates of immediate and early delayed reconstruction and disparities in the 1998 to 2000 timeframe versus 2005 to 2007 reported a significant increase in breast reconstruction rates, but with persistence of disparities (18). Similarly, our results show continued

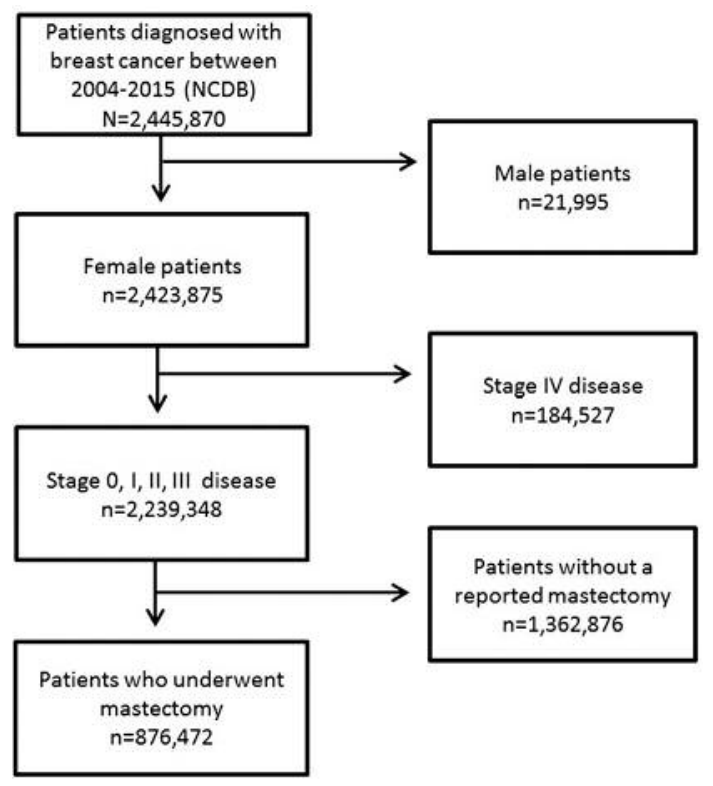

Figure 1. Flow chart depicting inclusion and exclusion criteria.

disparity, specifically in reconstruction by race, income level, insurance, and education level. Disparities in breast reconstruction based on race, income, and type of insurance are well documented, and several studies use databases with large numbers of patients $(9,11,22-31)$. In 2018, a retrospective analysis of the 2008 to 2012 California, Florida, and New York state inpatient and ambulatory surgery databases was reported (12). The authors concluded that African American, Hispanic, and Asian/Pacific Islander/Native Americans had lower rates of breast reconstruction when compared to Caucasians, even when stratifying patients by private insurance and residence in areas with a high density of plastic surgeons (12).

In our analysis, black, Asian, and Native American races were found to have a lower probability of getting an immediate or early delayed reconstruction when compared to white patients. Furthermore, government- and noninsured patients were found to have fewer reconstruction procedures than privately insured patients. This could be in part explained by the lower reimbursement that government insurance brings to providers. With the passing of the Women's Health and Care Rights Act in 1998, it would be logical to think that the rate of breast reconstruction would increase, but as shown by a previous study (32), these laws can also reduce breast reconstructions. In a survey of plastic surgeons, it was reported that $90 \%$ enjoyed doing a breast reconstructive procedure; however, $43 \%$ decreased their procedure volume due to insufficient reimbursement (32). Most of the articles focusing on large national databases have found disparities in 
the rate of breast reconstruction. However, in a study conducted by Enewold et al. (33) using data from the US Department of Defense's Central Cancer Registry and Military Health System Data Repository, results showed no indication that the receipt of reconstruction was different among races (33). This study was conducted in a population that had equal access to health care, suggesting that disparity reports can be confounded by unequal health care access.

Our study showed that living in a zip code with a lower income average or one in which fewer people have a high school diploma independently decreases the odds of getting a reconstructive procedure. As with race disparities, this result could be caused by less access to health care due to low income, lower education, or the sum of both factors. However, a study published in 2018 reviewing the National Surgical Quality Improvement Program database, reported a steady increase in the rate of breast reconstruction in the United States from 2005 to 2014 (13). When divided among racial groups, the increase was not proportional, resulting in reduced disparities (13).

Our study is not without limitations. Our analysis was conducted using the NCDB because it encompasses approximately $70 \%$ of all the cancer population in USA; however, its overall fidelity could be affected by individual centers' incomplete reports. The NCDB includes data for the primary treatment only, causing patients who received a delayed postmastectomy breast reconstruction to be registered as if they only had a mastectomy. For this reason, this study only includes immediate or early delayed reconstruction. The NCDB registers if the patient voluntarily decided to not undergo a surgical procedure, so it is not possible to exclude these patients from the study because it is not clear if they declined mastectomy, reconstruction, or another surgical procedure. Also, while the NCDB includes over 50 different races, we recoded the database to include white, black, Native American, and Asian to describe the most frequent races independently and group the least common ones. Additionally, reported income and education levels are based on the zip code where the patients reside rather than specific characteristics of the patients. This leads to assumptions about income or education level that might not be accurate for every patient.

Our study demonstrated that race, income, insurance, and education are factors that seem to have independently affected the rate of breast reconstruction in patients registered on the NCDB between 2004 and 2015. Even though many reports show a downtrend in disparities, they are still present. Efforts need to be made to reduce the health care gap in our society.

\section{Conflicts of Interest}

There are no conflicts of interest to declare regarding this study.

\section{Authors' Contributions}

Restrepo, Spaulding and Forte had full access to all of the data in the study and take responsibility for the integrity of the data and the accuracy of the data analysis. Study concept and design: Forte, Restrepo, Boczar, Huayllani, Sisti, and McLaughlin. Acquisition, analysis, or interpretation of data: Forte, Spaulding, and Restrepo. Drafting of the manuscript: Bagaria, Rinker, and Restrepo. Critical revision of the manuscript for important intellectual content: Boczar, Huaylliani, Sisti, Gabriel, McLaughlin, Bagaria, Spaulding, Rinker, and Forte. Statistical analysis: Restrepo, Spaulding, and Forte. Administrative, technical, or material support: Spaulding and Forte. Study supervision: Forte.

\section{Acknowledgements}

This study was supported, in part, by the Mayo Clinic Robert D. and Patricia E. Kern Center for the Science of Health Care Delivery.

\section{References}

1 Miller KD, Siegel RL, Lin CC, Mariotto AB, Kramer JL, Rowland $\mathrm{JH}$, Stein KD, Alteri R and Jemal A: Cancer treatment and survivorship statistics, 2016. CA Cancer J Clin 66(4): 271-289, 2016. PMID: 27253694. DOI: 10.3322/caac.21349

2 Asgeirsson KS, Rasheed T, McCulley SJ and Macmillan RD: Oncological and cosmetic outcomes of oncoplastic breast conserving surgery. Eur J Surg Oncol 31(8): 817-823, 2005. PMID: 16043322. DOI: 10.1016/j.ejso.2005.05.010

3 Sisti A, Grimaldi L, Tassinari J, Cuomo R, Fortezza L, Bocchiotti MA, Roviello F, D'Aniello C and Nisi G: Nipple-areola complex reconstruction techniques: A literature review. Eur J Surg Oncol 42(4): 441-465, 2016. PMID: 26868167. DOI: 10.1016/j.ejso. 2016.01 .003

4 Yang RL, Newman AS, Reinke CE, Lin IC, Karakousis GC, Czerniecki BJ, Wu LC and Kelz RR: Racial disparities in immediate breast reconstruction after mastectomy: Impact of state and federal health policy changes. Ann Surg Oncol 20(2): 399406, 2013. PMID: 23054106. DOI: 10.1245/s10434-012-2607-9

5 Kocher R, Emanuel EJ and DeParle NA: The affordable care act and the future of clinical medicine: The opportunities and challenges. Ann Intern Med 153(8): 536-539, 2010. PMID: 20733178. DOI: 10.7326/0003-4819-153-8-201010190-00274

6 Jones VC and Carlson GW: Disparities in immediate breast reconstruction after mastectomy: Time for a change. Breast $\mathrm{J}$ 20(4): 337-338, 2014. PMID: 24985527. DOI: 10.1111/tbj.12280

7 Shippee TP, Kozhimannil KB, Rowan K and Virnig BA: Health insurance coverage and racial disparities in breast reconstruction after mastectomy. Womens Health Issues 24(3): e261-269, 2014. PMID: 24794541. DOI: 10.1016/j.whi.2014.03.001

8 Iskandar ME, Dayan E, Lucido D, Samson W, Sultan M, Dayan JH, Boolbol SK and Smith ML: Factors influencing incidence and type of postmastectomy breast reconstruction in an urban multidisciplinary cancer center. Plast Reconstr Surg 135(2): 270e-276e, 2015. PMID: 25626810. DOI: 10.1097/prs.0000000000000 888

9 Mahmoudi E, Giladi AM, Wu L and Chung KC: Effect of federal and state policy changes on racial/ethnic variation in immediate postmastectomy breast reconstruction. Plast Reconstr Surg 135(5): 1285-1294, 2015. PMID: 25919243. DOI: 10.1097/prs.000000 0000001149 
10 Albornoz CR, Cohen WA, Razdan SN, Mehrara BJ, McCarthy CM, Disa JJ, Dayan JH, Pusic AL, Cordeiro PG and Matros E: The impact of travel distance on breast reconstruction in the united states. Plast Reconstr Surg 137(1): 12-18, 2016. PMID: 26710002. DOI: $10.1097 /$ prs.0000000000001847

11 Kamali P, Zettervall SL, Wu W, Ibrahim AM, Medin C, Rakhorst HA, Schermerhorn ML, Lee BT and Lin SJ: Differences in the reporting of racial and socioeconomic disparities among three large national databases for breast reconstruction. Plast Reconstr Surg 139(4): 795-807, 2017. PMID: 28350648. DOI: 10.1097/prs.000 0000000003207

12 Butler PD, Familusi O, Serletti JM and Fox JP: Influence of race, insurance status, and geographic access to plastic surgeons on immediate breast reconstruction rates. Am J Surg 215(6): 987-994, 2018. PMID: 29103529. DOI: 10.1016/j.amjsurg.2017.09.037

13 Epstein S, Tran BN, Cohen JB, Lin SJ, Singhal D and Lee BT: Racial disparities in postmastectomy breast reconstruction: National trends in utilization from 2005 to 2014. Cancer 124(13): 2774-2784, 2018. PMID: 29660760. DOI: 10.1002/cncr.31395

14 Kaplan CP, Karliner LS, Hwang ES, Bloom J, Stewart S, Nickleach D, Quinn J, Thrasher A and Napoles AM: The effect of system-level access factors on receipt of reconstruction among latina and white women with dcis. Breast Cancer Res Treat 129(3): 909-917, 2011. PMID: 21533531. DOI: 10.1007/s10549-011-1524-0

15 Kruper L, Holt A, Xu XX, Duan L, Henderson K, Bernstein L and Ellenhorn J: Disparities in reconstruction rates after mastectomy: Patterns of care and factors associated with the use of breast reconstruction in southern california. Ann Surg Oncol 18(8): 21582165, 2011. PMID: 21308486. DOI: 10.1245/s10434-011-1580-z

16 Morrow M, Li Y, Alderman AK, Jagsi R, Hamilton AS, Graff JJ, Hawley ST and Katz SJ: Access to breast reconstruction after mastectomy and patient perspectives on reconstruction decision making. JAMA Surg 149(10): 1015-1021, 2014. PMID: 25141939. DOI: $10.1001 /$ jamasurg.2014.548

17 Rosson GD, Singh NK, Ahuja N, Jacobs LK and Chang DC: Multilevel analysis of the impact of community $v s$ patient factors on access to immediate breast reconstruction following mastectomy in maryland. Arch Surg 143(11): 1076-1081; discusion 1081, 2008. PMID: 19015466. DOI: 10.1001/archsurg.143.11.1076

18 Sisco M, Du H, Warner JP, Howard MA, Winchester DP and Yao K: Have we expanded the equitable delivery of postmastectomy breast reconstruction in the new millennium? Evidence from the national cancer data base. J Am Coll Surg 215(5): 658-666; discussion 666, 2012. PMID: 22921327. DOI: 10.1016/ j.jamcollsurg.2012.07.008

19 Razdan SN, Cordeiro PG, Albornoz CR, Disa JJ, Panchal HJ, Ho AY, Momoh AO and Matros E: National breast reconstruction utilization in the setting of postmastectomy radiotherapy. J Reconstr Microsurg 33(5): 312-317, 2017. PMID: 28235218. DOI: $10.1055 / \mathrm{s}-0037-1598201$

20 Bilimoria KY, Stewart AK, Winchester DP and Ko CY: The national cancer data base: A powerful initiative to improve cancer care in the united states. Ann Surg Oncol 15(3): 683-690, 2008. PMID: 18183467. DOI: 10.1245/s10434-007-9747-3

21 Bannay A, Chaignot C, Blotiere PO, Basson M, Weill A, Ricordeau P and Alla F: The best use of the charlson comorbidity index with electronic health care database to predict mortality. Med Care 54(2): 188-194, 2016. PMID: 26683778. DOI: 10.1097/MLR.0000 000000000471

22 Alderman AK, McMahon L, Jr. and Wilkins EG: The national utilization of immediate and early delayed breast reconstruction and the effect of sociodemographic factors. Plast Reconstr Surg 111(2): 695-703; discussion 704-695, 2003. PMID: 12560690. DOI: 10.1097/01.PRS.0000041438.50018.02

23 Alderman AK, Hawley ST, Janz NK, Mujahid MS, Morrow M, Hamilton AS, Graff JJ and Katz SJ: Racial and ethnic disparities in the use of postmastectomy breast reconstruction: Results from a population- based study. J Clin Oncol 27(32): 5325-5330, 2009. PMID: 19805680. DOI: 10.1200/JCO.2009.22.2455

24 Agarwal S, Pappas L, Neumayer L and Agarwal J: An analysis of immediate postmastectomy breast reconstruction frequency using the surveillance, epidemiology, and end results database. Breast $\mathbf{J}$ 17(4): 352-358, 2011. PMID: 21615823. DOI: 10.1111/j.15244741.2011.01105.x

25 Offodile AC, 2nd, Tsai TC, Wenger JB and Guo L: Racial disparities in the type of postmastectomy reconstruction chosen. $\mathrm{J}$ Surg Res 195(1): 368-376, 2015. PMID: 25676466. DOI: 10.1016/j.jss.2015.01.013

26 Schumacher JR, Taylor LJ, Tucholka JL, Poore S, Eggen A, Steiman J, Wilke LG, Greenberg CC and Neuman HB: Socioeconomic factors associated with post-mastectomy immediate reconstruction in a contemporary cohort of breast cancer survivors. Ann Surg Oncol 24(10): 3017-3023, 2017. PMID: 28766209. DOI: 10.1245/s10434-017-5933-0

27 Yang RL, Newman AS, Lin IC, Reinke CE, Karakousis GC, Czerniecki BJ, Wu LC and Kelz RR: Trends in immediate breast reconstruction across insurance groups after enactment of breast cancer legislation. Cancer 119(13): 2462-2468, 2013. PMID: 23585144. DOI: $10.1002 /$ cncr.28050

28 Lang JE, Summers DE, Cui H, Carey JN, Viscusi RK, Hurst CA, Waer AL, Ley ML, Sener SF and Vijayasekaran A: Trends in postmastectomy reconstruction: A seer database analysis. J Surg Oncol 108(3): 163-168, 2013. PMID: 23861196. DOI: 10.1002/jso.23365

29 Hershman DL, Richards CA, Kalinsky K, Wilde ET, Lu YS, Ascherman JA, Neugut AI and Wright JD: Influence of health insurance, hospital factors and physician volume on receipt of immediate post-mastectomy reconstruction in women with invasive and non-invasive breast cancer. Breast Cancer Res Treat 136(2): 535545, 2012. PMID: 23053659. DOI: 10.1007/s10549-012-2273-4

30 Sharma K, Grant D, Parikh R and Myckatyn T: Race and breast cancer reconstruction: Is there a health care disparity? Plast Reconstr Surg 138(2): 354-361, 2016. PMID: 27465159. DOI: 10.1097/PRS.0000000000002344

31 Odom EB, Schmidt AC, Myckatyn TM and Buck DW, 2nd: A cross-sectional study of variations in reimbursement for breast reconstruction: Is a healthcare disparity on the horizon? Ann Plast Surg 80(3): 282-286, 2018. PMID: 28984659. DOI: 10.1097/SAP. 0000000000001228

32 Alderman AK, Atisha D, Streu R, Salem B, Gay A, Abrahamse P and Hawley ST: Patterns and correlates of postmastectomy breast reconstruction by u.S. Plastic surgeons: Results from a national survey. Plast Reconstr Surg 127(5): 1796-1803, 2011. PMID: 21532409. DOI: $10.1097 /$ PRS .0b013e31820cf183

33 Enewold LR, McGlynn KA, Zahm SH, Poudrier J, Anderson WF, Shriver CD and Zhu K: Breast reconstruction after mastectomy among department of defense beneficiaries by race. Cancer 120(19): 3033-3039, 2014. PMID: 24965236. DOI: 10.1002/cncr.28806

Received May 9, 2019

Revised May 24, 2019

Accepted May 24, 2019 